\title{
Further Evidence for Age and Area; its Applicability to the Ferns, \&c.
}

\author{
BY \\ J. C. WILLIS, M.A., Sc.D.
}

W

HEN once the regular graduation of species in a genus or family into series of what we may almost perhaps term 'wheels within wheels' (10, figs. pp. 336-7) has been pointed out, it needs but little investigation to convince oneself that the law of 'age and area' is general in its applicability. So long as it was only based on the estimates made by Trimen for the Ceylon flora, its foundations were by no means secure, but it was soon confirmed to a high degree of certainty by the results for the flora of New Zealand (9), where actual measurements of range were employed. Perhaps the most striking proof of the probable correctness of my deductions is the remarkable result given in Tables III to VI of that paper. The further investigation of the outlying islands of New Zealand (15) showed the operation of the law even more decisively if possible, at the same time giving what appears to me a fairly conclusive proof that the active factor in distribution is age (not youth) within the country.

It would therefore seem that the production of a few more pieces of confirmatory evidence, based like the figures for New Zealand upon actual measurements, should suffice to establish the hypothesis upon a firm basis. In the present paper I give five such pieces of evidence, three of which at the same time go to show that the hypothesis applies not only to the Angiosperms, to which alone I have confined it as yet, but also to the Coniferae and Ferns, and is therefore probably perfectly general in its application.

It is not usually possible to get such clear and convincing evidence as shows in the floras of Ceylon and New Zealand, where the plants can be split into three sections, graduated in order of rarity (Ceylon, CeylonPeninsular India, Wide; New Zealand, New Zealand and outlying islands, Wide), though the first and fourth cases given here are such. But once the graduation is seen to hold generally, it will suffice to parallel them in one or more features.

[Annals of Botany, Vol. XXXI. Nos. CXXIII and CXXIV. July and October, 19I7.] 


\section{The Orchids of Jamaica.}

In order to bring in a country as far removed from Ceylon and New Zealand as possible, I have taken Jamaica, of which a detailed flora is in course of publication by Messrs. Fawcett and Rendle (4), and have used the first volume, which contains the Orchids, a family exceptionally well known in the country.

To go into great detail is unnecessary, and I shall simply describe the method used and the results obtained. Taking a sheet of squared tracingpaper, I placed it over a large map of the island, and with the aid of the large official map identified and marked the localities given, I 62 (different) in all. A few of these I was not able to identify, especially such as Ramble, Retreat, and Belvidere, which appear upon the map in dozens of places. I thus noted for each species the squares in which it occurred, and for the unidentified localities I have simply allowed another square. This in actual fact adds almost exactly a square for every other species, but acts equally on all alike. Each of the larger squares of the tracing-paper covered an area approximately $6 \frac{3}{4}$ miles square.

To make a fair test of my hypothesis, and to enable comparison with Ceylon and New Zealand, I have divided the Orchids (I94 in all) into three groups-those endemic to Jamaica, those found in Jamaica and Cuba only, and those with wider distribution than this (wides). Adding up for every species the number of squares for which it is recorded, we get:

TABLE I.

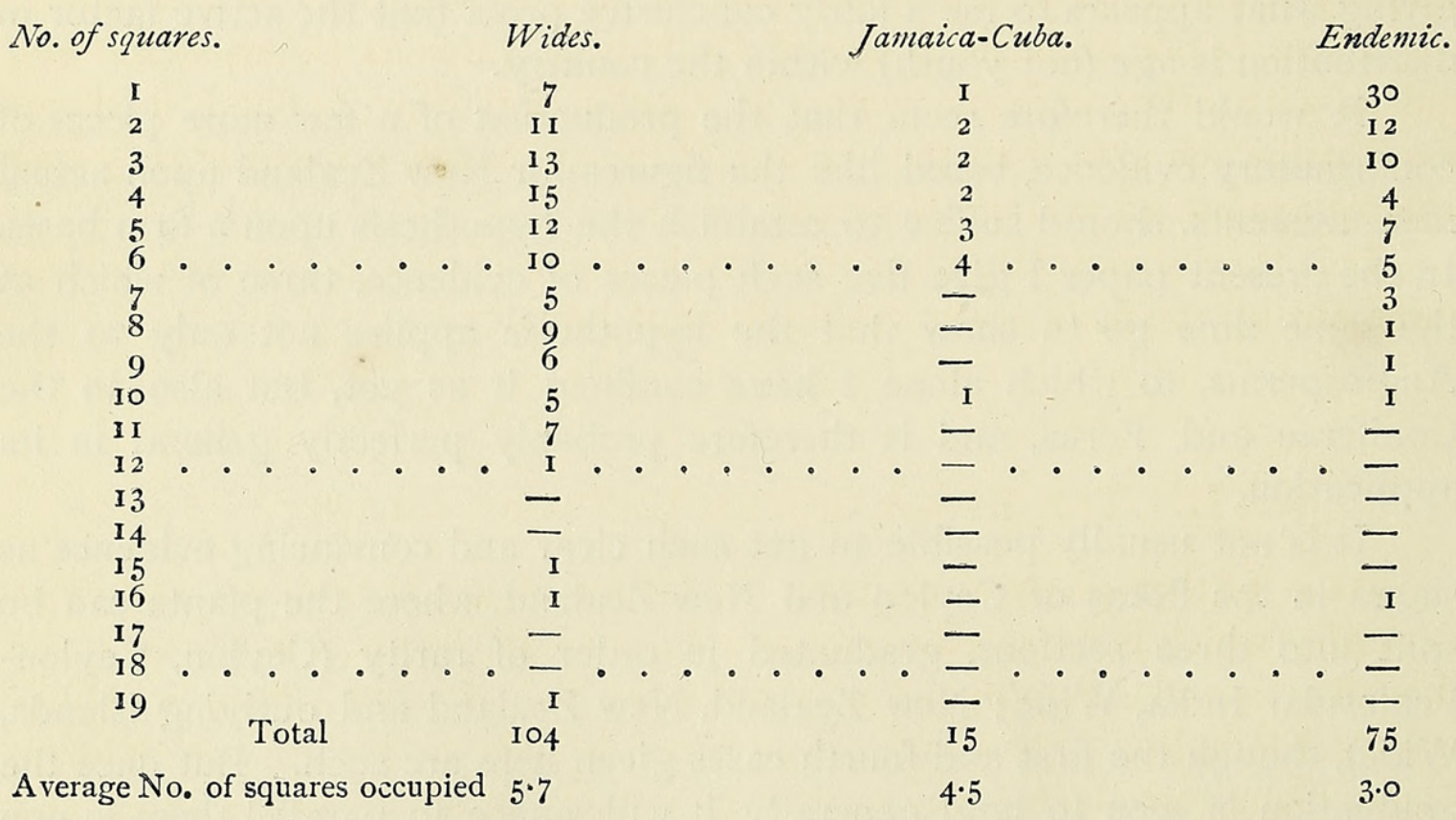

This result, it will be at once seen, is exactly parallel to that obtained for Ceylon and New Zealand. The wides occupy the largest area, the 
Jamaica-Cuba species the next, and the endemics the least. Nearly half the endemics are found in one square only. It is of interest to look at the seven wides which only occur in one square, and note that as usual one picks out the most uncertain species in the flora by this method. Epidendrum ciliare is a very conspicuous orchid, but is only recorded on the authority of a specimen 'from Jamaica' by Shepherd in Kew Herbarium. E. patens is assigned by Swartz to Jamaica, but no specimen has been seen. Pelexia adnata was found by Masson in I781, but has never been seen again. Pleurothallis Wilsonii is doubtfully identified with the Porto Rico and Guadeloupe specimens, and is perhaps more likely an endemic. This leaves only three, Vanilla phaeantha, Arpophyllum giganteum, and Epidendrum Ottonis, all collected by Harris, and therefore reliably recorded. Similarly, the one Cuba species that occupied only one square, Pleurothallis foliata, was recorded by Wilson (1846-58), and has never been seen again. This and others may quite well have been exterminated in the clearances that have gone on in the last eighty years.

Many may express surprise at the small number of squares from which even the wides are recorded, when it is realized that there are 130 squares in the island; and they may go on to say that further investigation will show that my figures are unreliable. But to this, as in the similar cases of Ceylon and New Zealand, the reply is simple-is there any reason to suppose that collectors deliberately collected wides in preference to JamaicaCubas, or to endemics? They are more often recorded simply because they occur more often, and there is no shadow of reason to suppose that the relative results would be affected by any amount of further investigation. And my results depend, not upon absolute figures, but upon comparative.

There is one endemic genus of Orchids in Jamaica (Homalopetalum), and as with other endemic genera in Ceylon and New Zealand, it shows less distribution area than the average of the endemics, occupying only two squares against an average of three.

It is thus abundantly clear that my hypothesis of age and area is fully borne out by the facts of the orchid flora of Jamaica.

\section{The Flora of the HaWAitan IsLands.}

As a further piece of evidence in favour of my hypothesis, and from a country which is extraordinarily rich in endemic forms, I have taken the Hawaiian islands, employing as a basis the list of plants given in Hillebrand's Flora (5). There are seven chief islands in the group-Niihau, Kauai, Oahu (on which is the capital, Honolulu), Molokai, Lanai, Maui, and Hawaii. They are separated from each other by stretches of water from ten to seventy miles in width, through which pass currents in a north- 
easterly or south-westerly direction, i. e. at right angles to the general direction of the group.

Taking for each member of the flora the number of islands upon which it has been found, one obtains the following result:

\section{TABLE II.}

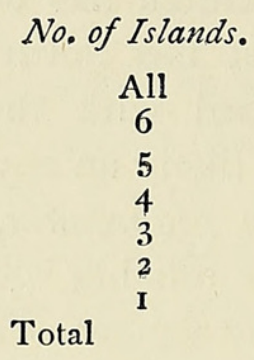

Rarity (in figures from $\mathrm{I}$ to $\gamma$ )

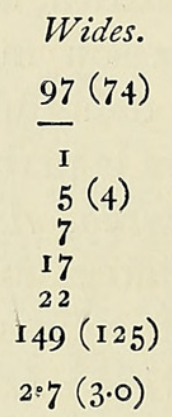

In great probability, however (see 5, Introduction, p. xvi), some of these wides, viz. twenty-three in those reaching all islands, and one reaching four, were introduced in prehistoric times, and as of the wides only reaching one island or two, most reach Oahu or Hawaii (the largest and most important islands, the former having a great port of call-Honolulu), probably many of the last two classes were recently introduced. This reduces the list of wides to 125 , and brings the rarity to $3 \cdot 0$, which, however, makes no difference to the argument.

From this table it is evident that on the whole the wides arrived in the group at an early period, and had already most of them spread over the whole of it before it broke up into the existing islands, which stand upon a submarine plateau. The way in which the wides reached the group does not matter to the present discussion, whether overland, or by other means. Only fifty-one of them arrived too late to spread over the whole of the islands before they became broken up, and of these there is good reason to suppose that many are comparatively very recent arrivals.

A considerable number of endemics were also evolved in time to reach the outer boundaries of the present archipelago before it broke up. It must be remembered that upon my hypothesis all plants, given long enough time and absence of serious barriers, will ultimately cover the whole area (cf. 11, p. 20, Table XIII, columns from G onwards). In the Hawaiian islands the whole area is mountainous, so that plants of all elevations can probably spread with comparatively equal facility, though it would seem probable that as the suitable areas of high elevation are of necessity smaller, in most cases, the plants of high altitudes would most often tend to spread less rapidly than those of low. This, therefore, must be added to the list of causes that may modify the action of age and area, as given in a previous paper (13, p. 206). 
The forty-one endemics found in all the islands are thus explained as due to the continual growth of the number by new arrivals from lower in the scale. But when the islands separated, there would still be many that had not yet covered the whole area, and as the endemics are younger, these would be more numerous than in the case of the wides, in proportion at any rate. They would increase in the usual way from those occupying large down to those occupying small areas. Once the islands were well separated, they would necessarily be confined, in the great majority of cases, each to its own island, its two islands, or whatever number it then occupied. The actual facts of the table above bear out these suppositions completely.

If, as there seems just reason to suppose, endemic species may themselves give rise to other endemics, then the numbers now found on one island are probably much in excess of those that actually occurred at the moment of separation. The sudden rise from II 3 on two islands to 273 on one goes to support this supposition.

The facts of the Hawaiian flora thus fit in easily with my hypothesis of 'age and area', but without considerable use of supplementary hypotheses, based merely on supposition, cannot be made to fit any other.

\section{The Distribution of Callitris in Australia.}

So far I have not attempted to include within the operation of my 'age and area' hypothesis anything but the Angiosperms, but a very little investigation shows that it is in reality more general. Happening to have in my possession a monograph of Callitris (1), I investigated its distribution. The genus is confined to Australia. C. glanca occupies the whole range of the genus, covering Australia and Tasmania. Two species come into a second class, C. verrucosa (New South Wales to West Australia) and C. tasmanica (New South Wales to Tasmania), while a third class includes C. robusta, Drummondii, calcarata, intratropica, arenosa, rhomboidea, Macleayana, and propinqua. Lastly, a fourth class-those of very narrow distribution-includes C. oblonga, gracilis, Muelleri, tuberculata, Roci, Morrisoni, and a $s p$. nov. Considering the small size of the genus (eighteen species), this grouping fits in very well with my hypothesis, and goes to show that it applies also to the Coniferae.

\section{The Ferns of New Zealand.}

I shall now go on to show, in two short essays, that the Ferns also follow the law of 'age and area'. In order to reduce the fern floras of New Zealand and Hawaii to a common denominator in a group in which the nomenclature has been so much in a state of flux, I have used the names as settled by Christensen (3), but the result is almost exactly the same as if I had left them untouched. 
Leaving age and area entirely out of the consideration, it is generally accepted that the Ferns are on the whole a much older group than the Angiosperms. One may therefore obtain a good crucial test as to whether it is age or youth that goes with area occupied. If the endemics be older species dying out, then it is evident that fern endemics should occupy less area than angiosperm endemics; but if, on the other hand, my hypothesis be accepted, then they should occupy more. The actual facts give us for the Ferns :

\section{TABLE III.}

Wides (including those only reaching the outlying islands) Endemic to New Zealand proper

$\begin{array}{cc}\text { Number. } & \begin{array}{c}\text { Rarity } \\ \text { (Figs. } \mathbf{1 - 1 0 )}\end{array} \\ 104 & \mathbf{3 \cdot 2} \\ 24 & 3 \cdot 8\end{array}$

The corresponding figures for Angiosperms (9, p. 449) were 3.5 and 6.5 . The Ferns therefore, whether wide or endemic, show a wider distribution in New Zealand than the Angiosperms. This is especially the case with the endemic Ferns, which range on an average 724 miles, against a range of 400 for an angiosperm endemic. ${ }^{1}$ This agrees with what is required under my hypothesis, but is very difficult to harmonize with the idea that endemics are old species dying out.

Why, whilst the endemics show this great difference in favour of the Ferns, the wides should only show an increased range of thirty-six miles is not altogether clear. The explanation which I would suggest is that as we know that fern spores may be carried to great distances by the wind, and as we have actual examples in which Ferns have arrived in new places over considerable distances with no intermediate halting-places, e. g. the summit of Ritigala in Ceylon (12), or the sterilized island of Krakatoa near Java $(6,8)$, land connexion is not so necessary as it is in the case of Angiosperms. There is no reason why new Ferns should not occasionally arrive in New Zealand subsequently to the breaking of the land bridge, though the figures already given rather go to show that most of them arrived by that way. If we accept this hypothesis, which is not very far-fetched, there is no difficulty in understanding why there are so many wides with but a small range in New Zealand, though they may be widely dispersed abroad. It does not affect the question of the endemics, because one of these which became established beyond the sea would cease to be an endemic. Nor does this behaviour of the wides give any encouragement to the supporter of Natural Selection, or of the idea of dying out of old species.

We may get a clearer insight into this question by splitting the Ferns of New Zealand into four groups, according as to whether they do or do

1 Each unit of rarity represents I 20 miles of range; 6.5 means 400 miles, 5.5 means 520 , and so on. 
not reach the outlying islands (Kermadecs, Chathams, Aucklands), or some of them. This gives us the following table:

TABLE IV.

\begin{tabular}{|c|c|c|c|c|}
\hline Range in $N . Z$. & $\begin{array}{l}\text { Wides } \\
\text { reaching } \\
\text { Islands. }\end{array}$ & $\begin{array}{l}\text { Wides not } \\
\text { reaching } \\
\text { Islands. }\end{array}$ & $\begin{array}{l}\text { Endemics } \\
\text { reaching } \\
\text { Islands. }\end{array}$ & $\begin{array}{l}\text { Endemics not } \\
\text { reaching } \\
\text { Islands. }\end{array}$ \\
\hline I00I-1080 miles & $27^{1}$ & 4 & $5^{3}$ & 5 \\
\hline $88 \mathrm{I}-1000$ & $12^{2}(2 \mathrm{~K})$ & 8 & I & 5 \\
\hline $76 \mathrm{I}-880$ & I & 3 & 2 & 5 \\
\hline $641-760$ & $\mathrm{I}(\mathrm{K})$ & 8 & I & 2 \\
\hline $521-640$ & $\mathrm{I}(\mathrm{K})$ & 9 & 2 & 2 \\
\hline $401-520$ & - & 5 & - & - \\
\hline $281-400$ & I $(\mathrm{K})$ & 5 & I & I \\
\hline $16 I-280$ & I (K) & 3 & - & I \\
\hline $4^{1-160}$ & - & I & - & I \\
\hline $0-40 \quad$, & - & 2 & 一 & 2 \\
\hline Total & 44 & 48 & 12 & 24 \\
\hline Rarity & $I \cdot 7$ & 4.6 & $2 \cdot 8$ & $3 \cdot 8$ \\
\hline Angiosperms & $2 \cdot 4$ & 3.9 & $2 \cdot 8$ & $6 \cdot 5$ \\
\hline
\end{tabular}

$\mathrm{K}$ means a species reaching the Kermadecs only among the islands, though ranging beyond them into the rest of the world.

This is a very interesting table. In the first place, it shows that a sprinkling of wides have come in from the Kermadecs, which have supplied part of its flora to, as well as received part of their flora from, New Zealand. If we subtract those which only reach the Kermadecs among the islands, we get 27 in Class I, IO in Class II, and I in Class III with an average rarity of $\mathrm{I} \cdot 3$, or nearly as widespread in New Zealand as possible. The 10 all range to Foveaux Strait, which evidently was formed very early in the geological history of New Zealand. The one species in Class III ranges from Stewart Island up to 200 miles south of North Cape, and reaches the Chatham, Auckland, Campbell, and Antipodes islands, as well as Australia.

Turning to the second column, the first thing one notices is the irregular graduation of the numbers from top to bottom. This is a very strong point in favour of my suggestion made above, that many of these wides may have entered New Zealand after the breaking of the land bridges. Only 8 of the 48 reach Stewart Island; Io more reach Foveaux Strait, and 23 reach the North Cape. Their ranges are much more scattered about the islands than those of the species in the first column, which again is a point in support of my hypothesis. It is also favoured by the fact that the rarity of these species is much greater than that of the

1 Reaching in all 53 of the three chief groups (K., Ch., Au.), and $\mathbf{I} 8$ other groups (Campb., Antip., Macquarie, \&c.).

2 Reaching in all 14 of the three chief groups, and three others.

3 Reaching in all 6 of the three chief groups. 
corresponding Angiosperms, which are much less able than the Ferns to pass over long stretches of water. The rarity of the Ferns which had also reached the islands is much less than that of the corresponding Angiosperms, as would be expected by reason of their greater age.

It will be noticed that the fern wides which do not reach any islands are rarer than the endemics which do not do so. On my hypothesis as to the late arrival of some of the Ferns, this is intelligible enough, but it is an awkward difficulty for the Natural Selectionist, or the supporter of the idea of the dying out of endemics.

Passing on to the third column, one notices at once that the endemics, as would be expected from their age, show a marked accumulation at the top, and this is also shown in the last column, though, as would be expected, the latter shows more species in the lower classes. The one endemic in the third column that is below the fifth class has a range that includes the Chathams, Aucklands, and Antipodes, and evidently only touched New Zealand with the outer part of its circle of distribution : its centre of origin was probably somewhere between the Chathams, Aucklands, and Antipodes.

The three chief groups of islands are the Kermadecs (north), Chathams (east), and Aucklands (south), and it is interesting to note the proportionate numbers that reach them :

\section{TABLE V.}

Reaching.
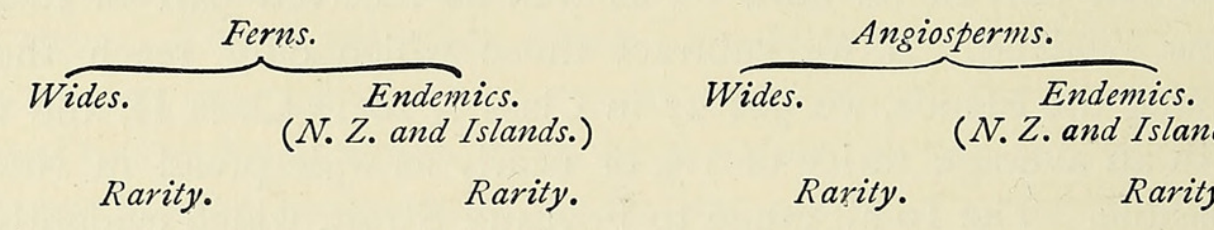

(N. Z. and Islands.)

\begin{tabular}{|c|c|c|c|c|c|c|c|c|}
\hline & & Rarity. & & Rarity. & & Rarity. & & Rarity. \\
\hline K., Ch., Au. & 7 & $I \cdot O$ & - & - & 4 & $I \cdot O$ & - & - \\
\hline $\begin{array}{l}\text { K., Ch. } \\
\text { Ch., Au. }\end{array}$ & $\left.\begin{array}{r}4 \\
10\end{array}\right\} I_{4}$ & $\left.\begin{array}{l}I \cdot 2 \\
1 \cdot 0\end{array}\right\} 1 \cdot 07$ & $\left.\begin{array}{l}\text { I } \\
\text { I }\end{array}\right\} 2$ & $\left.\begin{array}{r}\begin{array}{r}I \cdot 0 \\
z \\
g\end{array}\end{array}\right\} 4 \cdot 0$ & $\left.\begin{array}{l}\text { I6 } \\
\text { I I }\end{array}\right\} 27$ & $\left.\begin{array}{l}\mathrm{I} \cdot 3 \\
2 \cdot 6\end{array}\right\} \mathrm{I} \cdot 8$ & $\left.\begin{array}{l}8 \\
9\end{array}\right\}$ I & $\left.\begin{array}{l}2 \cdot 2 \\
2 \cdot 3\end{array}\right\} 2 \cdot 2$ \\
\hline${ }^{\mathrm{K} .} \mathrm{Ch} .{ }_{\mathrm{Au}}$ & $\left.\begin{array}{r}6 \\
17 \\
-\end{array}\right\} 23$ & $\left.\begin{array}{l}4 \cdot 6 \\
I \cdot 5\end{array}\right\} 2 \cdot 3$ & $\left.\begin{array}{r}- \\
5 \\
4\end{array}\right\} 9$ & $\left.\begin{array}{l}\bar{I} \cdot 8 \\
3 \cdot 5\end{array}\right\} 2 \cdot 5$ & $\left.\begin{array}{l}16 \\
36 \\
10\end{array}\right\} 62$ & $\left.\begin{array}{l}3 \cdot 6 \\
1 \cdot 6 \\
4 \cdot 6\end{array}\right\} 2 \cdot 6$ & $\left.\begin{array}{r}7 \\
33 \\
34\end{array}\right\} 74$ & $\left.\begin{array}{l}3 \cdot 8 \\
1 \cdot 8 \\
4 \cdot 0\end{array}\right\} 3 \cdot 0$ \\
\hline Total & 44 & & II & & 93 & & $9 \mathrm{I}$ & \\
\hline \multicolumn{4}{|c|}{ Total of wides in N. Z. $9^{2}$} & & 301 & & & \\
\hline
\end{tabular}

The Ferns are distinctly the more widespread group: the first class (K., Ch., Au.) should be especially noted, and it should be observed that all its members, both Ferns and Angiosperms, show the maximum possible commonness in New Zealand, ranging the islands from end to end. The second degree of commonness is found in the second class, the third in the third, with the single exception of the endemic fern reaching the Chathams and Aucklands.

If my hypothesis be accepted, another prediction may be made as

\footnotetext{
1 Perhaps a case of accidental transport, but see above on this page.
} 
follows. No other hypothesis, be it noted, allows of any predictions. One will expect the Ferns to show a graduated arrangement by zones similar to that shown by the Angiosperms in Tables III to VI (9), and as they are on the whole a good deal older, one will expect them to have spread farther along the islands of New Zealand, so that the curves should be flatter. At the same time, one will expect to find them taking less notice of the presence of Cook's Strait, as they were probably developed early enough to have crossed that part of New Zealand before the strait was formed. Turning to the actual facts, one gets :

TABLE VI.

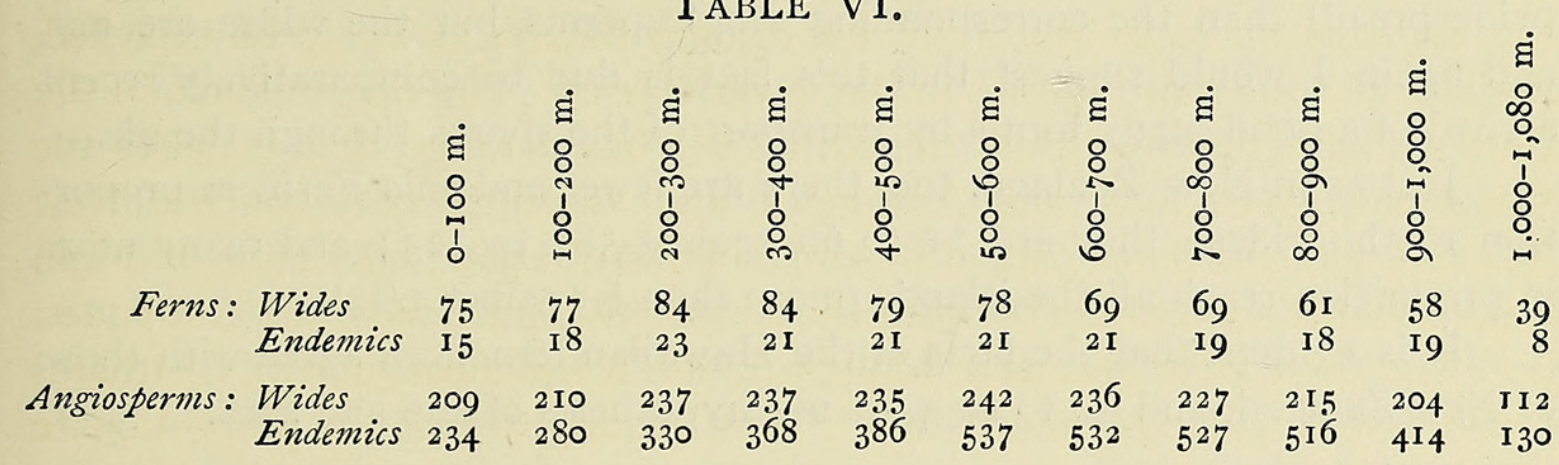

It is evident that the prediction is borne out by the facts. The fern curves are flatter, and they, as well as the 'wide' Angiosperms, take no notice of Cook's Strait (between the $5^{\text {th }}$ and 6th figures), which holds up so many endemic Angiosperms. Similarly, they take less notice of Foveaux Strait, between the last two figures. One gathers the impression that the angiosperm wides and the fern endemics are on the whole of somewhere about the same period, very broadly speaking.

Another prediction one may make is that as the Ferns are older, more (proportionately) should have reached the outlying islands. This one finds to be the case, for 44 out of 92 do so, against 95 out of 301 Angiosperms.

More of the Ferns, too, should have reached even farther than this, and thus those that were once endemic would have become wides, leaving a smaller proportion of endemics. The fern endemics are only 24 to 92 , against 902 angiosperm endemics to 301 wides.

It is thus clear that the Ferns also obey the law of age and area, and throw a good deal of light upon various problems associated with it.

\section{The Ferns of the Hawaitan Islands.}

Taking the Ferns from Hillebrand's Flora (5), and naming them afresh from Christensen's Index, one gets the following : 
TABLE VII.

$\begin{array}{ccccc}\text { Islands. } & \text { Wides. } & \text { Angiosp. } & \text { Endemic. } & \text { Angiosp. } \\ \text { All } & 36 & 74 & 20 & 4 \mathrm{I} \\ 6 & -2 & -1 & 5 & 8 \\ 5 & 2 & 4 & 5 & \text { II } \\ 4 & 7 & 7 & 10 & 85 \\ 3 & 8 & 17 & 14 & 113 \\ 2 & 5 & 22 & 17 & 273 \\ \text { I } & 60 & 125 & 7 \mathrm{I} & 58 \mathrm{I} \\ \text { Total } & 3.0 & 4.3 & 5.5 \\ \text { Rarity (figures I-7) } & 2.8 & & \end{array}$

As in New Zealand the endemics are a good deal more common (widespread) than the corresponding Angiosperms, but the wides are not, and again I would suggest that this fact is due to comparatively recent arrival of a good many forms by transport of the spores through the air.

Just as in New Zealand, too, there are fewer endemic Ferns in proportion to the wides; they are $7 \mathrm{I}$ to 60 against $58 \mathrm{I}$ to $\mathrm{I} 25$; and many more in proportion reach all the islands (more than $\frac{1}{4}$ against $\mathrm{I} / \mathrm{I} 4$ ).

It is evident that the facts of the Hawaiian fern flora agree with those of New Zealand, and go to support my hypothesis of age and area.

It is thus evident that the law of age and area is very general, if not universal, in its applicability. The Orchids of Jamaica show its operation as clearly as did the floras of Ceylon and New Zealand. The distribution of the flora of the Hawaiian islands agrees with it; that of Callitris in Australia shows that it probably applies to Coniferae, and that of the Ferns of New Zealand and Hawaii that the Ferns also obey the same law.

In the Ferns of both countries, there appears a very clear departure from the normal trend of the figures, though it is not in a direction to encourage those who believe in Natural Selection as governing areal distribution, or in the hypothesis that endemics are old species dying out. In both cases the endemics, which must on the whole be older than the endemic Angiosperms, are much more widespread than the latter, as would be expected upon my hypothesis. The wides, however, do not show this; they have only a slightly greater distribution than the angiosperm wides. It is evident that this is probably due to the same cause in both cases, and I have suggested that it is due to the fact that Ferns may be easily carried as spores, and so may continue to arrive up to the most recent times.

But if we accept the law as thus wide and general in its applicability, it is evident that it must have some bearings upon other branches of botanical work, and it may be worth while briefly to call attention to some of these, in so far as they affect lines in which I have myself worked.

In systematic botany, for example, the tendency in recent times, as 
exemplified in Engler and Prantl's 'Natürlichen Pflanzenfamilien', has been to split up the older families into smaller, and to a certain extent to do the same with the genera. This splitting is on the whole fully justifiable, and there are yet some cases, it seems to me, where it will have to be done; but, on the other hand, there is no doubt that it may easily be carried too far. From my work on age and area it is now fairly clear that in systematic work the geographical factor should be taken into consideration to a greater extent than has hitherto been the case. In the last twenty years the tendency has undoubtedly been in this direction, and the genera and families are tending more and more to be split into groups which show geographical as well as structural affinities. But it would seem as if more stress yet must be laid upon the former.

The figures given in my various papers on this subject afford no evidence to show that any species are actually dying out. Many people at once jump to the conclusion that by this I mean that no species are dying out, but this is by no means the case. What the figures show is that such cases are too few to be seen in them in an unmistakable way-and this fact, by the way, shows much more clearly in those sets of figures which (as in the case of New Zealand) are the result of actual measurement, than in the figures for Ceylon, which were merely estimates. New Zealand may quite well contain $20-30$ or more species which are in process of dying out, but their presence is not shown by the figures, and could not be, unless they all belonged to one or two families.

But if this be so, then it is no longer safe to assume a greater discontinuity in distribution than may be accounted for by known geological changes, except in those cases where we may with reasonable probability invoke accidental transport by air or water. And no isolated example of geographical discontinuity can be accepted as of value without other confirmatory cases. Numerous North Temperate Zone species, for example, occur again in Australia or New Zealand, without there being any in the intermediate regions, so far as we know. This we may perhaps put down to alternating glacial periods. Fern spores again, we know, may be carried almost indefinite distances by wind, and may germinate if on arrival they strike a suitable spot. Probably this does not often happen, but it almost certainly does at times occur, so that we may accept as quite possible any distribution that may occur for any group of Ferns, without needing any other supplementary hypotheses.

But in the flowering plants such long-distance transport is very rare, and we have little evidence to show that it occurs for instance between one continent and another. Probably the Orchids and Composites are best suited to such transport. On the summit of Ritigala, for example, which is separated by about 40 miles of 'dry' country from other 'wet' mountain country in Ceylon, I found (12) 49 wind-carried wet-zone plants. Of these 
no less than 24 were Ferns or Lycopodiums, and 20 Orchids, while the remaining five were made up of two each from the Compositae and Asclepiadaceae, and one of the Apocynaceae. It is thus evident that even at a range of 40 miles most of the parachute mechanisms begin to break down. In any case the families in which long-distance transport by wind may occur are few. Or, to take the case of dispersal by birds, there is little or no good evidence for any beyond, say, at the most I,000 miles. Or yet again, where there is a marine current, transport may occur by its means to great distances, provided the climates at the two ends are not hopelessly dissimilar. In the Maldives, for example, Prof. J. Stanley Gardiner and myself (16) showed that several of the water-borne species must probably have come from Malaya or from the Seychelles-a long distance in either case.

But there are quite a number of cases in which none of these causes can be called in as aid, and yet a great discontinuity is accepted in the geographical distribution. To take an extreme instance, the genus Cryptotaenia, DC. (Umbelliferae), is described as having one species in Canada, one in Calabria, and one in the Cameroons. If there were, say, twenty to thirty more with the same distribution, then it is obvious that some explanation would have to be found. But with this one case only, it is evident that the identification of these three species as belonging to the same genus must rest upon the convergence of evolution or upon a parallel development or polyphyly $(14$, p. 446). Such cases are very numerous, though there are not many with quite so marked a discontinuity as that quoted.

Or, as another case, let us take the family Lardizabalaceae, sometimes split off from Berberidaceae, chiefly on the ground of climbing habit, unisexual flowers, and polycarpellary ovary. There are seven genera, of which five occupy the region from the Khasia Mts. (Assam) to Japan, whilst Boquila and Lardizabala are found in Chile. Now if the first five were found in Australia or New Zealand, this would be normal enough; these countries have many groups in common with temperate S. America, and even species. But from eastern Asia to Chile is too great a gap. The fleshy fruit could not be carried by birds to such a distance in such a direction, and we have no longer any right to invoke the dying out of linking forms in the intermediate region, without direct evidence. It may have occurred, but we require evidence to prove it. This being so, it seems to me almost impossible, on the present evidence, to regard the Lardizabalaceae as a monophyletic unit. The two isolated groups may have had a common ancestor not very far back, but on the existing evidence it will be safer to reunite them to Berberidaceae (or Menispermaceae, if preferred), as two separate sub-groups. This is a thesis which might easily be developed to any extent, but I have simply chosen these two examples to illustrate my main point, that geographical affinity is required as well as structural in settling relationship. 
It appears to me very unsafe to assume that two very similar forms are necessarily very nearly related when they live in places as to whose former geological connexion we have no evidence, and between which accidental transport is almost impossible. Other evidence than mere structural similarity is now required to prove close relationship. We must have geographical affinity as well. A number of groups at present accepted as monophyletic will probably prove to be more or less polyphyletic, as is proving to be the case with the old and once apparently well-defined genus Acrostichum (2).

Again, it is worth while pointing out that 'age and area' gives strong evidence in favour of mutation. If we accept infinitesimal variation literally, it is, as pointed out in a recent paper $(13$, p. 202), easy to evolve anything, but four provisos, and they are all very large, must be made. Unfortunately for Natural Selection, none of them can be shown to hold good, and the result has been gradually to force its supporters, as illustrated in Mr. Ridley's recent paper (7), to abandon infinitesimal variation, and postulate for something larger. They have not yet fully realized that by doing this they have really abandoned the essential point of their position. There is no evidence to show that a small-not infinitesimal-variation in one direction can be followed by others in the same direction. To take the examples given on p. 203 (13), can it for a moment be supposed that the formation of bulbils in Asplenium and many other plants began in easy stages, not to speak of infinitesimal? Can one conceive of them as beginning as rudimentary bulbils? Or can one expect to see a slightly dehiscent berry, a partially reversed leaf ? How can intermediate stages exist between cauliflory and normal flowering, between pollen and pollinia (especially pollinia with translators-an essential family character, the only one really discriminating Asclepiadaceae from Apocynaceae), between sympodia and monopodia? If once really infinitesimal variation is abandoned, there seems nothing for it but to take the plunge and admit that mutations of considerable size may occur. And if so, Natural Selection cannot be causative.

But to return to the bearings of age and area on the question, it seems clear that it shows that endemic species confined to small areas are in reality, in the great majority of cases, new species commencing their career. At the commencement of their life, and for a long period afterwards, Natural Selection comes in, but chiefly as an agent to determine the non-survival of really disadvantageous mutations. How many of these occur we have no means of knowing; those which survive are but few in number-only 902 in New Zealand since very far back in time. These one may look upon as having successfully passed through the Natural Selection sieve, but, as I have already pointed out, a very small accident may easily kill out other commencing species which, if left uninterfered with, might also have passed through. A fire on a mountain-top in Ceylon might easily kill a local 
endemic. Didymocarpus Perdita, Ridley, perhaps belongs to this class. Mr. Ridley ( 7, p. 555) collected two specimens, and the species has never been seen again; probably he exterminated it in its earliest stages. Christisonia albida, Thw., found (once only) at Hakgala in Ceylon, has never been seen again, though there is a botanic garden there, and the forest has been most carefully ransacked. Thwaites describes it as white, so that perhaps it was weeded out by Natural Selection for lack of the brownish colouring matter of its family, and yet it was so different in other features as well that Hooker accepted it as a Linnean species.

Once this early stage is passed, my work on age and area goes to show that the further distribution of species depends on their mere age far more than on any other factor.

But the species which are thus found commencing, and which have apparently passed through the Natural Selection sieve, are not, in the great majority of cases, distinguished from their congeners of the same country simply by small and unimportant differences, but by well-marked characters, which very often are sufficiently numerous and well defined to rank the species as Linnean.

In the case of Coleus elongatus, for example, the species is distinguished from $C$. barbatus, its nearest relative, and from all other species of Asia, by the peculiar raceme-like inflorescence, and by the five equal teeth of the calyx, in place of the one large upper and four small lower teeth of other Colei.

Unless, therefore, evidence can be brought up to prove that such species have arisen by the dying out, or the killing out, of intermediate forms, there seems nothing for it but to admit that considerable mutations may take place. In numerous cases, too-for instance, Coleus elongatus-intermediate stages are not possible, so that probability goes against supposition of the dying out of intermediate forms. In any case, 'age and area', taken together with previous work, speaks very strongly in favour of mutation as the immediate means by which new species have arisen.

\section{Summary.}

Five further pieces of evidence are given, confirming, and extending the application of, the hypothesis of age and area.

The range of the Orchids of Jamaica is shown to go in the orderendemics least, Jamaica-Cuba species next, wides greatest.

The flora of Hawaii is shown to be easily explicable on the same hypothesis, the wides ranging much more than the endemics, which are graduated down to a maximum (in one island only).

Callitris is taken as an example to show that Coniferae are also included in the operation of the law. 
The Ferns of New Zealand and Hawaii are also studied. The endemic species show a much greater range than the endemic Angiosperms, a result to be expected on my hypothesis, but contrary to what one would expect if endemics are dying out. The wides only range a trifle farther than the wide Angiosperms, which I put down to the probability that new species may arrive after the breaking of the land bridges. Cf. especially the numbers and rarities in Table $\mathrm{V}$.

Lastly, it is pointed out that more care must be taken, in view of these results, to consider geographical as well as structural relationship in forming genera and families, and that this work gives strong evidence in favour of mutation.

\section{LITERATURE CITED.}

1. BAKer and Smith: Pines of Australia, Sydney, I9Io.

2. Bower : Phylogeny of the Filicales. Ann. Bot., vol. xxxi, I9I7, p. I.

3. Christensen : Index Filicum, Copenhagen, 1906.

4. FAwCETt and Rendle : Flora of Jamaica, vol. i, London, I9io.

5. Hillebrand : Flora of Hawaii, 1888.

6. Penzig: Flora of Krakatoa. Ann. Buitenz., 2. iii.

7. Ridley : Endemism and the Mutation Theory. Ann. Bot., vol. xxx, I9I6, p. $55^{\mathrm{I}}$.

8. Treub : Flora of Krakatoa. Ann. Buitenz., I. vii.

9. Willis : Distribution of Species in N. Zealand. Ann. Bot., vol. xxx, I9I6, p. 437.

10. - Endemic Flora of Ceylon. Phil. Trans., B, vol. ccvi, 1915, p. 307 .

11. - Evolution of Species in Ceylon. Ann. Bot., vol. xxx, I916, p. I.

12. - : Flora of Ritigala. Ann. R. B. G., Perad., vol. iii, I906, p. 27 I.

13. - Relative Age of Endemic Species. Ann. Bot., vol. xxxi, I91 7, p. 189.

14. — : Studies in ... Podostemaceae... Ann. R. B. G., Perad., vol. i, 1902, p. 267 (especially p. 446).

15. : The Distribution of the Plants of the Outlying Islands of New Zealand. Ann. Bot., vol. $x x x i, 1917$, p. 327 .

16. - and Gardiner: Flora of the Maldives. Ann. R. B. G., Perad., vol. i, I902, p. 45. 


\section{$2 \mathrm{BHL}$ Biodiversity Heritage Library}

Willis, J. C. 1917. "Further evidence for age and area; its applicability to the ferns, \&c." Annals of botany 31, 335-349.

https://doi.org/10.1093/oxfordjournals.aob.a089651.

View This Item Online: https://www.biodiversitylibrary.org/item/232813

DOI: https://doi.org/10.1093/oxfordjournals.aob.a089651

Permalink: https://www.biodiversitylibrary.org/partpdf/320194

\section{Holding Institution}

Smithsonian Libraries

\section{Sponsored by}

Biodiversity Heritage Library

\section{Copyright \& Reuse}

Copyright Status: Not in copyright. The BHL knows of no copyright restrictions on this item.

This document was created from content at the Biodiversity Heritage Library, the world's largest open access digital library for biodiversity literature and archives. Visit BHL at https://www.biodiversitylibrary.org. 